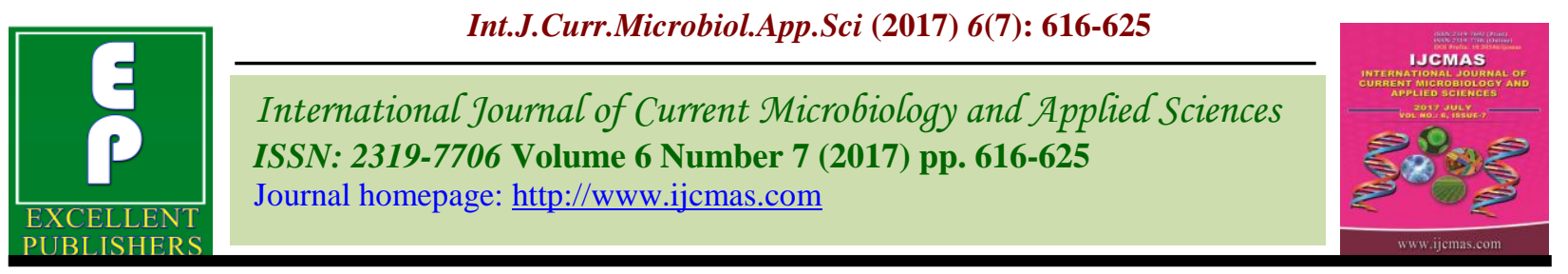

Original Research Article

https://doi.org/10.20546/ijcmas.2017.607.075

\title{
Screening of Native Rhizobia and Pseudomonas Strains for Plant Growth Promoting Activities
}

\author{
G. Thirumal*, R. Subhash Reddy, S. Triveni, Y. Nagaraju and B. Prasannakumar \\ Department of Agricultural Microbiology and Bioenergy, College of Agriculture, Professor Jaya \\ Shankar Telangana State Agricultural University, Rajendranagar, Hyderabad - 500 030, \\ Telangana, India \\ *Corresponding author
}

\section{A B S T R A C T}

\begin{tabular}{|l|}
\hline Ke y w or d s \\
Rhizobium, \\
Pseudomonas, \\
Potassium, Zinc, \\
IAA. \\
\hline Article Info \\
\hline $\begin{array}{l}\text { Accepted: } \\
\text { 14 June } 2017 \\
\text { Available Online: } \\
\text { 10 July } 2017\end{array}$ \\
\hline
\end{tabular}

Plant growth-promoting rhizobacteria (PGPR) are naturally occurring soil bacteria that aggressively colonize plant roots and benefit plants by providing growth promotion. Inoculation of crop plants with certain strains of PGPR at an early stage of development improves biomass production through direct effects on root and shoots growth. During the past couple of decades, plant growth-promoting rhizobacteria (PGPR) will begin to replace the use of chemicals in agriculture, horticulture, sylvicultural, and environmental cleanup strategies. In this present study, different Rhizobial and Pseudomonas strains from different locations were collected and evaluated for their potential PGP activity. Among ten Rhizobial cultures GNR1 recorded the highest P solubilization zone $(24.3 \mathrm{~mm})$ conversely, $\mathrm{P}$ solubilization is highest in Pseudomonas isolates. Five cultures of Rhizobia and six cultures of Pseudomonas were able to solubilize potassium. The solubilisation zone is ranging from a maximum of 11.6 to a minimum of $8.3 \mathrm{~mm}$. All the ten Rhizobial cultures and five Pseudomonas cultures were able to release of zinc from insoluble forms of zinc. All the Rhizobial and Pseudomonas isolates were positive for IAA production.

\section{Introduction}

The rhizosphere is a nutrient-rich habitat and harbors a huge variety of bacteria and fungi that each can have neutral, beneficial or deleterious effects on the plant (Berendsen et al., 2012). Some of these organisms can improve plant growth by different mechanisms (Lugtenberg et al., 2009; Van der Ent et al., 2009). Fluorescent Pseudomonas is an important groups of plant growth-promoting microorganism reported to protect plants against pathogens by evolving various mechanisms such as antagonism, competition and Induced systemic resistance (ISR) (Harman et al., 2004; Kloepper et al.,
1980). The productive efficiency of a specific PGPR may be further enhanced with the optimization and acclimatization according to the prevailing soil conditions (Ahemad et al., 2014). The bacteria lodging around/in the plant roots (rhizobacteria) are more versatile in transforming, mobilizing, solubilizing the nutrients compared to those from bulk soils (Hayat et al., 2010).

Therefore, the rhizobacteria are the dominant deriving forces in recycling the soil nutrients and consequently, they are crucial for soil fertility (Glick, 2012). PGPR have been 
reported to directly enhance plant growth by a variety of mechanisms: fixation of atmospheric nitrogen, solublization of minerals such as phosphorus, production of siderophores, and synthesis of plant growth hormones i.e. Indole-3- acetic acid (IAA), gibberellic acid, cytokinins, and ethylene (Nelson, 2014). Indirect mechanisms involves the biological control of plant pathogens and deleterious microbes, through the production of antibiotics, lytic enzymes, hydrogen cyanide, catalase and siderophore or through competition for nutrients and space can improve significantly plant health and promote growth, as evidenced by increases in seedling emergence, vigor, and yield (Khan, 2006). After $\mathrm{N}_{2}$ fixation, Phosphate (P) solubilization is very important plant growth promoting activity. A large proportion of soluble inorganic phosphate added to the soil is fixed as insoluble forms soon after the application and become unavailable to the plants (Rodriquez and Fraga, 1999). Several soil bacteria particularly belonging to genera Bacillus and Pseudomonas possess the ability to change insoluble forms into soluble form by secreting organic acids as formic acid, acidic, propionic, lactic, glycolic, fumaric and succinic acid (Vazquez et al., 2000). Biofertilizers such as microbial inoculants promote plant growth, productivity and increase the nutrient status of the host plant have internationally been accepted as an alternative source of chemical fertilizers (Vessey, 2003). Significant increases in crop yields have been reported by applying PGPR microbial inoculants (Salamone, 2000).

Rhizobia are Gram-negative chemoorganotrophic or chemolithotrophic soil bacteria belonging to the family Rhizobiaceae. These obligate aerobes, form nodules on roots of leguminous species, or on the roots and stems of the leguminous plant Sesbaniarostrate (Werner, 1992). Because of its ability to fix atmospheric nitrogen, the symbiotic association between rhizobia and legumes has been intensively studied. However, many reports found in literature strongly suggest that these bacteria beneficial for legumes have also excellent potential to be used as PGPR with non-legumes. In fact, rhizobia like other PGPR are capable of colonizing the roots of non-legumes forming an associative interaction and they produce phytohormones, siderophores and HCN. Some strains are also antagonistic towards several plant pathogenic fungi.

\section{Materials and Methods}

The present study was carried out at the Department of Agricultural Microbiology and Bioenergy, College of Agriculture, Rajendranagar, PJTSAU, Hyderabad. Pure cultures of Plant Growth Promoting Rhizobium and Pseudomonas isolates collected from different laboratories tables 1 and 2. Attempts were made to assess the screening and characterization of isolates with multiple beneficial properties like, mineral phosphate solubilization and production of Plant Growth Promoting substances.

\section{Morphological and biochemical characterization}

The isolated and collected bacteria were studied for their morphological like gram reaction, pigmentation, cultural characteristics and biochemical characteristics like Indole production, methyl red, Voges-Praskaure's test, citrate utilization test, oxidase, catalase and sugar fermentation tests.

\section{Screening for plant growth promoting properties}

Screening for different plant growth promoting properties such as mineral solublization like Phosphorus Solubilisation (Pikovskaya, 1948), Zinc Solubilization, 
(Saravanan et al., 2003), Potassium releasing (Prajapati and Modi, 2012), Plant growth promoting substances such as IAA production (Gorden and Weber, 1951), biocontrol activity such as HCN production (Castric and Castric, 1983) and Siderophore production (Schwynand Neilands, 1987) and antifungal activity with soil born plant pathogens. Pure cultures were screened for following Plant Growth Promoting properties.

\section{Phosphate Solubilization}

For this test, sterilized Pikovskaya's agar was poured as a thin layer on to the sterilized petri plates and incubated for $24 \mathrm{~h}$.

After incubation, the Pikovskaya's plates were spot inoculated with pure cultures and incubated at $28 \pm 1^{\circ} \mathrm{C}$ for $4-5$ days. Formation of a clear zones around the colonies were considered as positive result for phosphate solubilization (Pikovskaya, 1948)

PSE (Phosphate Solubilization Efficiency) = Z / C x 100 Z- Clearance zone including bacterial growth

\section{C- Colony diameter}

\section{Potassium solubilization}

The cultures which are collected from laboratories were test for potassium solubilization by spotting technique using modified Aleksandrov medium containing 0.2 $\%$ insoluble mica powder or potassium alumino silicate as insoluble potassium source. The plates were incubated at $28 \pm 2^{\circ} \mathrm{C}$ in BOD incubator for 3-4 days (Prajapati and Modi, 2012). Detection of potassium solubilization by different Rhizobium and Pseudomonas isolates was based upon the ability of solubilization zone formation. The Rhizobium and Pseudomonas strains /isolates were maintained by transfer on to Aleks and
Rovagar medium slants. These bacterial cultures were stored at $4^{\circ} \mathrm{C}$ in refrigerator for further use.

\section{Zinc solubilization}

The cultures which are collected from laboratories were tested for zinc solubilization by spotting technique using mineral salts agar medium was amended with $0.1 \%$ of either insoluble zinc oxide $(\mathrm{ZnO})$ or zinc phosphate. The plates were incubated at $28 \pm 2^{\circ} \mathrm{C}$ incubator for 3-4 days. Detection of zinc solubilization by different Rhizobium and Pseudomonas isolates were based upon the ability of solubilization zone formation. The Rhizobium and Pseudomonas strains/isolates were maintained by transferring on mineral salts agar medium slants. These bacterial cultures were stored at $4{ }^{\circ} \mathrm{C}$ in refrigerator for further use (Saravanan et al., 2003).

\section{Indole acetic acid production}

Indole acetic acid production was tested according to Gorden and Webber (1951). The active culture of each test isolate was raised in $5 \mathrm{ml}$ respective broth tubes and incubated at determined temperature and time. After incubation cultures were centrifuged at recommended rpm and time. Two drops of Ophosphoric acid was added to $2 \mathrm{ml}$ of supernatant and incubated for $30 \mathrm{~min}$ to develop the color. Development of pink color considered as positive for IAA production.

\section{Siderophore production}

Siderophore production was estimated qualitatively. Chrome Azurol S (CAS) Agar medium (Schwyn and Neilands, 1987): For the detection of siderophores, each Pseudomonas isolate was grown in synthetic medium, containing $0.5 \mu \mathrm{M}$ of iron and incubated for $24 \mathrm{~h}$ on a rotary shaker at room temperature. Chrome Azurol S (CAS) assay 
was used to detect the siderophores. The CAS plates were used to check the culture supernatant for the presence of siderophores. Culture supernatant was added to the wells made on the CAS agar plates and incubated at room temperature for $24 \mathrm{~h}$. Formation of yellow to orange coloured zone around the well indicates siderophore production.

\section{Hydrogen Cyanide Production (HCN)}

The HCN production was tested by the method of Castric and Castric (1983). First respective media plates i.e., YEMA (Rhizobium) and Kings B agar (Pseudomonas flourescence) were prepared separately and incubated for $24 \mathrm{~h}$. After that, $1 \mathrm{ml}$ of culture of each test isolate was inoculated on respective media plates separately. A disc of what man filter paper No.1 of the diameter equal to the petri plate size, impregnated with alkaline picric acid solution $(0.5 \%$ picric acid (w/v) in $1 \%$ sodium carbonate) was placed in the upper lid of the inoculated Petri plates under aseptic condition. The control plate did not receive the inoculum. The plates were incubated-upside up at $28 \pm 2^{\circ} \mathrm{C}$ for $48-72 \mathrm{~h}$. Change in color from yellow to light brown, moderate or strong reddish brown was taken as indication of $\mathrm{HCN}$ production.

\section{Results and Discussion}

The cultures were characterized, identified based on morphological and biochemical characteristics and studied for their plant growth promoting properties. The results of Screening of PGP properties are discussed below

\section{Phosphate solubilization}

Among ten Rhizobial cultures, seven cultures were able to solubilize phosphate on Pikovskaya's media containing Tri calcium phosphate in the range of $12.3 \mathrm{~mm}$ to $24.3 \mathrm{~mm}$ and depicted in graph 1. Among seven Rhizobial cultures GNR1 recorded the highest solubilization zone $(24.3 \mathrm{~mm})$ followed by RR2 (20.3 mm), GGR1 (19.3mm), BGR1 (18.3mm), SYR1 (16.3mm), GNR2 (15.3 $\mathrm{mm})$ and less solubilization by SFR2 (12.3mm) (Table 3 and Graph 1). Similar results were reported by phosphate solubilizing microorganisms Bacillus subtilis and Bacillus cereus isolated by Maheshwar and Sathiyavani (2012) from the groundnut rhizosphere soil, showed maximum phosphate solubilizing zone.

Among fifteen Pseudomonas pure cultures seven cultures were able to solubilize phosphate on Pikovskaya's media containing tri calcium phosphate in the range of $26.3 \mathrm{~mm}$ to $7.3 \mathrm{~mm}$. Among seven Pseudomonas cultures, RGP1 recorded the highest solubilization zone $(26.3 \mathrm{~mm})$ followed by PVP1 (19.3 mm), MP1 (16.3 mm) PRP2 (15.3 $\mathrm{mm})$, PSP2 (13.3mm) and DGP1 (12.3mm) and less solubilization by PSmP (7.3.mm) (Table 4 and Graph 1). Fekadu (2013) stated that Pseudomonas fluorescens that possessed promising properties of phosphate solubilization on Pikovskaya media by forming a clear halo zone.

\section{Potassium solubilization}

Among the ten Rhizobial cultures, five cultures were able to solubilize potassium on Alexondrov's medium containing $0.2 \%$ of potassium alumino silicate, as a source of insoluble potassium. The solubilization zone is ranging from a maximum of 11.6 to a minimum of $8.3 \mathrm{~mm}$. The isolate GNR1 has shown the maximum solubilization zone of $11.6 \mathrm{~mm}$ followed by BGR1 (10.3 mm), GGR1 (9 mm), RR1 (8.4 mm), and with least solubilization zone observed in SFR1 (8.3 $\mathrm{mm}$ ) (Table 3 and Graph 1). Similar results were reported by Kalavati et al., (2012) who isolated and screened for potassium 
solubilizing fungi from ceramic industry soils on Alexandrov agar medium supplemented with $0.5 \%$ potassium aluminium silicate.

Whereas among fifteen Pseudomonas isolates, six cultures were able to solubilize potassium on Alexondrov's medium containing $0.2 \%$ of potassium alumino silicate, as a source of insoluble potassium. The solubilization zone is ranging from a maximum of 13.3 to a minimum of $8.3 \mathrm{~mm}$. The cultures PSP2 has shown the maximum solubilization zone of $13.3 \mathrm{~mm}$ followed by RGP1 (12.3 mm), RGP2 and PVP1 (11.6mm), PRP2 (10.6mm), and with least solubilisation zone observed in PSmP (8.3 mm) (Table 4 and Graph 1).

\section{Zinc solubilization}

Among ten Rhizobial cultures were able tested for their efficiency for releasing of zinc.

The solubilization zone is ranging from 11.3 $\mathrm{mm}$ to $8.3 \mathrm{~mm}$ followed by SFR2 (10.3mm) SYR1, GNR2 (9.3 mm), and with least solubilization zone observed in GGR1 (8.3 mm) (Table 3 and Graph 1). Rehab (2015) investigated in biosorption for zinc $\left(\mathrm{Zn}^{2+}\right)$ and cadmium $\left(\mathrm{Cd}^{2+}\right)$ using living and lyophilized biomass of a bacterial strain isolated from waste water. Pazhaniraja and Prabudoss (2014) investigated the efficiency of $G$. diazotrophicuson zinc solubilization.

Table.1 List of Rhizobial cultures collected from different sources

\begin{tabular}{|c|c|c|c|}
\hline S. No & Isolate & Crop & Source \\
\hline 1 & GGR1 & Green gram & $\begin{array}{c}\text { Department of soil and biology, } \\
\text { ICRISAT, Hyderabad }\end{array}$ \\
\hline 2 & GGR2 & Green gram & $\begin{array}{c}\text { Biofertilizers laboratory, ARS, } \\
\text { Amaravathi, Guntur (dist), A.P }\end{array}$ \\
\hline 3 & GNR1 & Ground nut & $\begin{array}{c}\text { Microbiology lab, college of } \\
\text { Agriculture, R, Nagar, Hyd. }\end{array}$ \\
\hline 4 & GNR2 & Ground nut & $\begin{array}{c}\text { Department of soil and biology, } \\
\text { ICRISAT, Hyderabad. }\end{array}$ \\
\hline 5 & SFR1 & Sun Flower & $\begin{array}{c}\text { Biofertilizers laboratory, ARS, } \\
\text { Amaravathi, Guntur (dist), A.P. }\end{array}$ \\
\hline 7 & SFR2 & Sun Flower & $\begin{array}{c}\text { Department of soil and biology, } \\
\text { ICRISAT, Hyderabad }\end{array}$ \\
\hline 8 & RR1 & Rice & $\begin{array}{c}\text { Biofertilizers laboratory, ARS, } \\
\text { Amaravathi, Guntur (dist), A.P }\end{array}$ \\
\hline 9 & BGR1 & Rlack gram & $\begin{array}{c}\text { Microbiology lab, college of } \\
\text { Agriculture, R, Nagar, Hyd. }\end{array}$ \\
\hline 10 & SYR1 & Soybean & $\begin{array}{c}\text { Department of soil and biology, } \\
\text { ICRISAT, Hyderabad }\end{array}$ \\
\hline
\end{tabular}


Table.2 List of Pseudomonas cultures collected from different sources

\begin{tabular}{|c|c|c|c|}
\hline $\begin{array}{l}\text { S. } \\
\text { No }\end{array}$ & Isolate & Crop & Source \\
\hline 1 & PVP1 & Rice & $\begin{array}{c}\text { Biofertilizers laboratory, ARS, Amaravathi, Guntur } \\
\text { (dist), A.P. }\end{array}$ \\
\hline 2 & DBP & Rice & Department of soil and biology, ICRISAT, Hyderabad \\
\hline 3 & DGP1 & Rice & Department of soil and biology, ICRISAT, Hyderabad \\
\hline 4 & DMuP & Rice & $\begin{array}{l}\text { Biofertilizers laboratory, ARS, Amaravathi, Guntur } \\
\text { (dist), A.P. }\end{array}$ \\
\hline 5 & PSmP & Rice & Microbiology lab, college of Agriculture, R, Nagar, Hyd. \\
\hline 6 & PGuP1 & Rice & Department of soil and biology, ICRISAT, Hyderabad. \\
\hline 7 & PKP & Rice & Microbiology lab, college of Agriculture, R, Nagar, Hyd. \\
\hline 8 & PRP2 & Rice & $\begin{array}{c}\text { Biofertilizers laboratory, ARS, Amaravathi, Guntur } \\
\text { (dist), A.P }\end{array}$ \\
\hline 9 & PSP2 & Rice & Department of soil and biology, ICRISAT, Hyderabad \\
\hline 10 & DMP2 & Maize & Department of soil and biology, ICRISAT, Hyderabad \\
\hline 11 & RGP1 & Red gram & $\begin{array}{c}\text { Biofertilizers laboratory, ARS, Amaravathi, Guntur } \\
\text { (dist), A.P }\end{array}$ \\
\hline 12 & RGP2 & Red gram & Department of soil and biology, ICRISAT, Hyderabad. \\
\hline 13 & MP1 & Maize & Microbiology lab, college of Agriculture, R, Nagar, Hyd. \\
\hline 14 & MP2 & Maize & $\begin{array}{l}\text { Biofertilizers laboratory, ARS, Amaravathi, Guntur } \\
\text { (dist), A.P }\end{array}$ \\
\hline 15 & SFP1 & $\begin{array}{l}\text { Sun } \\
\text { Flower }\end{array}$ & Microbiology lab, college of Agriculture, R, Nagar, Hyd. \\
\hline
\end{tabular}

Table.3 Screening of Rhizobium isolates for plant growth promoting activities in vitro

\begin{tabular}{|c|c|c|c|c|c|}
\hline S. No & Isolates & $\begin{array}{c}\text { IAA production } \\
(\boldsymbol{\mu g} / \mathbf{m l})\end{array}$ & $\begin{array}{c}\text { Ammonia } \\
\text { production }\end{array}$ & $\begin{array}{c}\text { Siderophore } \\
\text { production }\end{array}$ & $\begin{array}{c}\text { HCN } \\
\text { production }\end{array}$ \\
\hline 1 & GGR1 & 41.3 & ++ & ++ & + \\
\hline 2 & GGR2 & 43.6 & + & +++ & ++ \\
\hline 3 & GNR1 & 59.9 & +++ & ++ & ++ \\
\hline 4 & GNR2 & 57.6 & ++ & +++ & ++ \\
\hline 5 & SFR1 & 33.5 & + & - & + \\
\hline 6 & SFR2 & 32.0 & ++ & + & ++ \\
\hline 7 & RR1 & 47.5 & + & - & + \\
\hline 8 & RR2 & 48.0 & + & ++ & + \\
\hline 9 & BGR1 & 34.8 & +++ & +++ & ++ \\
\hline 10 & SYR1 & 46.2 & ++ & +++ & ++ \\
\hline & C.D. & $\mathbf{1 . 4 0 1}$ & & & \\
\hline & SE(m) & $\mathbf{0 . 4 7 2}$ & & & \\
\hline & C.V. & $\mathbf{1 . 8 3}$ & & & \\
\hline
\end{tabular}

+ Weak production ++ Moderate production +++ Strong production

- No production IAA - Indole Acetic Acid 
Table.4 Screening of Pseudomonas isolates for plant growth promoting activities in vitro

\begin{tabular}{|c|c|c|c|c|c|}
\hline S. No & Isolates & $\begin{array}{c}\text { Siderophore } \\
\text { production }\end{array}$ & $\begin{array}{c}\text { IAA } \\
\text { production } \\
(\boldsymbol{\mu g} / \mathbf{m l})\end{array}$ & $\begin{array}{c}\text { Ammonia } \\
\text { production }\end{array}$ & HCN production \\
\hline 1 & PVP1 & - & 25.7 & ++ & ++ \\
\hline 2 & DBP & +++ & 22.0 & + & ++ \\
\hline 3 & DGP1 & ++ & 32.16 & + & + \\
\hline 4 & DMuP & +++ & 36.1 & +++ & ++ \\
\hline 5 & PSmP & - & 31.8 & + & + \\
\hline 6 & PGuP1 & + & 44.8 & ++ & ++ \\
\hline 7 & PKP & - & 41.8 & + & + \\
\hline 8 & PRP2 & ++ & 25.1 & + & + \\
\hline 9 & PSP2 & ++ & 28.9 & ++ & ++ \\
\hline 10 & DMP2 & ++ & 48.5 & + & + \\
\hline 11 & RGP1 & +++ & 57.4 & +++ & + \\
\hline 12 & RGP2 & +++ & 57.3 & + & + \\
\hline 13 & MP1 & +++ & 36.3 & + & + \\
\hline 14 & MP2 & ++ & 38.7 & ++ & + \\
\hline 15 & SFP1 & +++ & 31.9 & + & + \\
\hline & CD & & $\mathbf{1 . 1 7 0}$ & & + \\
\hline & SE( $\pm d)$ & & $\mathbf{0 . 4 0 3}$ & & + \\
\hline
\end{tabular}

- No production IAA - Indole Acetic Acid HCN - Hydrogen Cyanide

+ Weak production ++ Moderate production +++ Strong production

Graph.1 P, K and Zn solubilization zonesby Rhizobia and Pseudomonas isolates

\section{$\mathrm{P}, \mathrm{K}$ and $\mathrm{Zn}$ solubilization zones}

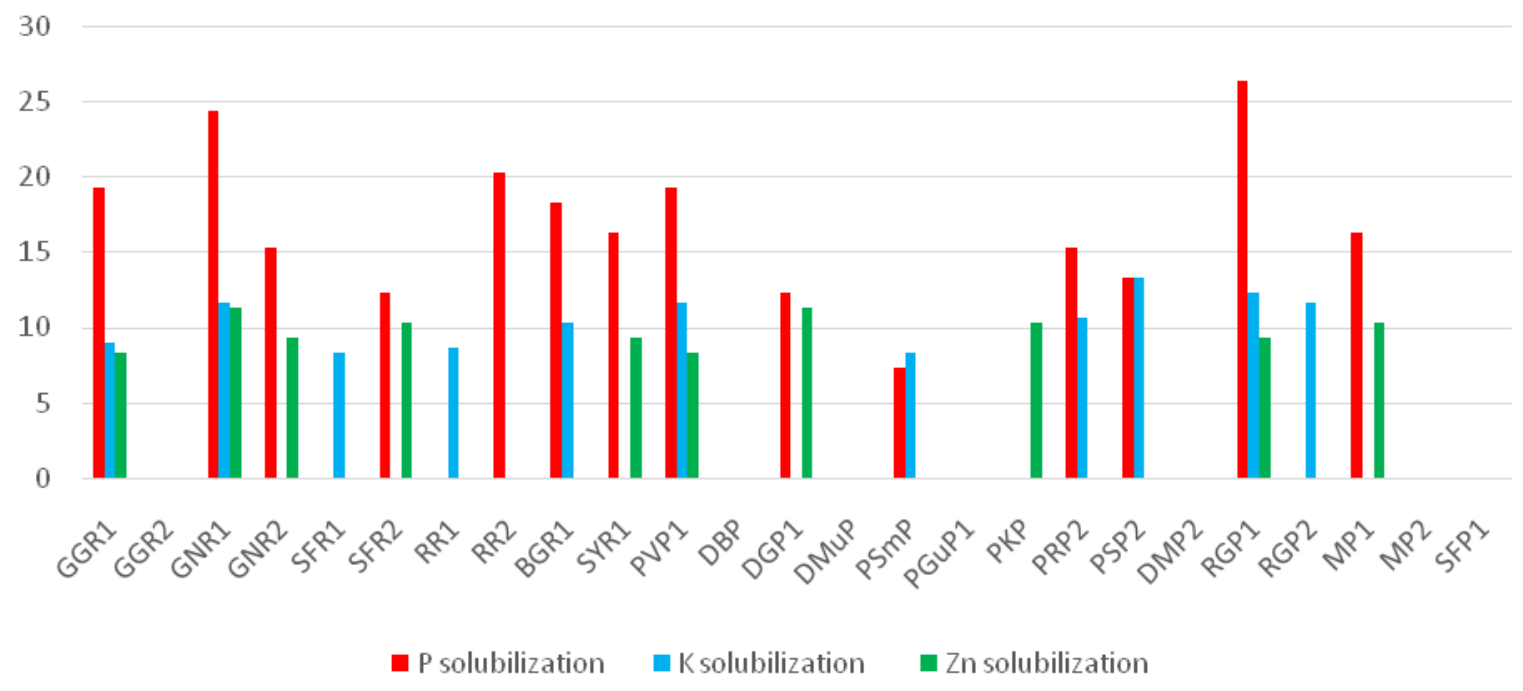


Among fifteen Pseudomonas isolates, five cultures were tested for their efficiency for releasing of zinc.

The solubilization zone was ranging from $11.3 \mathrm{~mm}$ to $8.3 \mathrm{~mm}$ followed by DGP1 (10.3mm) PKP, MP1 (10.3mm), RGP2 $(9.3 \mathrm{~mm})$ and with least solubilization zone observed in PVP1 (8.3mm) (Table 4 and Graph 1).

\section{IAA production}

All Rhizobial purecultures were shown positive for IAA production. Out of ten cultures, GNR1 $\left(59.9 \mu \mathrm{gml}^{-1}\right) \quad$ showed maximum IAA production, followed by GNR2 $\left(57.6 \mu \mathrm{gml}^{-1}\right), \mathrm{RR} 2\left(48.0 \mu \mathrm{gml}^{-1}\right), \mathrm{RR} 1$ $\left(47.5 \mu \mathrm{gml}^{-1}\right), \quad$ SYR1 $\left(46.2 \mu \mathrm{gml}^{-1}\right), \quad$ GGR2 $\left(43.6 \mu \mathrm{gml}^{-1}\right), \quad$ GGR1 $\left(41.3 \mu \mathrm{gml}^{-1}\right), \quad$ BGR1 $\left(34.8 \mu \mathrm{gml}^{-1}\right)$, SFR1 $\left(33.5 \mu \mathrm{gml}^{-1}\right)$, and SFR2 $\left(32.0 \mu \mathrm{gml}^{-1}\right)$ (Table 3).

All Pseudomonas isolates showed IAA production. Out of fifteen isolates, RGP1 (57.4 $\mu \mathrm{g} \mathrm{ml} \mathrm{ml}^{-1}$ ) exhibited maximum IAA production and followed by RGP2 (57.3 $\mu \mathrm{g}$ $\left.\mathrm{ml}^{-1}\right)$ DMP2 (48.5 $\left.\mu \mathrm{gml}^{-1}\right), \mathrm{RGuP1}\left(44.8 \mu \mathrm{gml}^{-1}\right)$, PKP $\left(41.8 \mu \mathrm{gml}^{-1}\right), \mathrm{MP} 2\left(38.7 \mu \mathrm{g} \mathrm{ml}^{-1}\right), \mathrm{MP} 1$ $\left(36.3 \mu \mathrm{gml}^{-1}\right), \quad \mathrm{DMuP}\left(36.1 \mu \mathrm{gml}^{-1}\right), \quad$ DGP1 $\left(32.1 \mu \mathrm{gml}^{-1}\right), \quad$ SFP1 $\quad\left(31.9 \mu \mathrm{gml}^{-1}\right), \quad$ PSmP $\left(31.8 \mu \mathrm{gml}^{-1}\right), \quad$ PSP2 $\quad\left(28.9 \mu \mathrm{gml}^{-1}\right), \quad$ PVP1 $\left(25.7 \mu \mathrm{gml}^{-1}\right)$, PRP2 $\left(25.1 \mu \mathrm{gml}^{-1}\right)$ and DBP (22.0 $\mathrm{g} \mathrm{ml}^{-1}$ ) (Table 4).

Saranraj (2013) isolated ten Pseudomonas fluorescens isolates obtained from the rhizosphere of paddy and tested for their efficiency of IAA production. The maximum IAA production was recorded by the isolate PF-8.

The minimum production of IAA was found in PF-4 isolates. The isolate Pseudomonas fluorescens (PS-8) showed maximum IAA production.
Biocontrol activities of Rhizobial and Pseudomonas cultures

\section{Siderophore production}

Out of ten Rhizobium cultures, eight were able to produce siderophores and remaining two were showed negative (SFR1, RR1). Out of eight cultures four viz., GGR2, GNR2, BGR1, SYR1 exhibited strong (+++) siderophore production and GGR1, GNR1 and RR2 produced moderately (++). Whereas the remaining one culture SFR2 were detected as weak (+) for Siderophore production. Arora et al., (2001) stated that siderophore production by Rhizobial strains has been considered as a potential way to improve nodulation and $\mathrm{N}_{2}$ fixation in iron deficiency conditions. Out of fifteen Pseudomonas pure isolates, twelve were showed siderophore production. Among the twelve cultures DBP, DMuP, RGP1, RGP2, MP1, SFP1 exhibited strong (+++) siderophore production and DGP1, PRP2, PSP2, DMP2, MP2 produced moderately $(++)$. Whereas the remaining one isolate PGup1 was detected as weak (+) for siderophore production and PVP1, PSmP, PKP were negative for siderophore production.

\section{Production of HCN}

HCN production is attributed as one of the mechanisms of biocontrol activity of the PGPR, the ability of the 25 isolates to produce HCN was determined by the picric acid assay. Ten Rhizobium cultures, were produced HCN. Further, the cultures, GGR2, GNR1, GNR2, SFR2, BGR1, SYR1 scored as moderate (++) for $\mathrm{HCN}$ production, whereas the remaining 4 isolates viz., GGR1, SFR1, RR1, RR2, found to be weak (+) in HCN production (Table 3 ).

Fifteen Pseudomonas pure isolates were showed HCN production. Out of fifteen, five viz., PVP1, DBP, DMuP, PGuP RGP of 
which detected as moderate $(++)$ for $\mathrm{HCN}$ production. Whereas the remaining ten cultures viz., DGP1 PSmP, PKP, PRP2, PSP2, DMP2, RGP2, MP1, MP2, SFP1 were scored as weak (+) for HCN production (Table 4). Yogendra (2013) reported that plant growth promoting characteristics such as Indole acetic acid (IAA) capacity, ability to produce ammonia $\left(\mathrm{NH}_{3}\right)$ and production of hydrogen cyanide were evaluated in three Rhizobacteria isolated from rhizosphere of pigeon pea. HCN production was observed in $33 \%$ isolates.

In conclusion, the plant growth promoting phenomenon can be attributed to the ability of the isolate to produce IAA, as IAA positively influences root growth and development, thereby enhancing nutrient uptake. It is a well-established fact that improved phosphorous nutrition influences overall plant growth and root development. Plant microbe interaction in Rhizosphere must increase before we can presume that utilization of PGPR as biofertilizers will determine a sustainable promotion of host plants growth. Combinations of beneficial bacterial strains that interact synergistically are currently being devised and numerous recent studies have shown a promising trend in the field of inoculation technology. PGPR are excellent model systems which can provide biotechnologist with novel genetic constituents and bioactive chemicals having diverse uses in agriculture and environmental sustainability.

\section{References}

Ahemad M, Kibret M (2014) Mechanisms and applications of plant growth promoting Rhizobacteria: Current perspective. Journal of King Saud University- Science 26: 1-20.

Arora, N.K., Ekta, K., Narain, R and Maheshwari, D.K. 2008. Sawdust as a superior for production of multipurpose bioinoculant using plant growth promoting Rhizobium spp and pseudomonas spp strains and their impact on productivity of Trifolium repense. Research Communications Current Science.95 (1).

Berendsen RL, Pieterse CM, Bakker PAHM (2012) the rhizosphere microbiome and plant health. Trends in Plant Science 17: 478-486.

Castric, K.F and Castric, P.A. 1983. Method for rapid detection of cyanogenic bacteria. Applied and Environmental Microbiology. 45: 700-702.

Glick BR (2012) Plant Growth-Promoting Bacteria: Mechanisms and Applications. Hindawi Publishing Corporation, Scientifica. Biotechnol. 17: 319-339.

Gorden, A.S and Weber, R.P. 1951. Colorimetric estimation of Indole Acetic Acid. Plant Physiology. 26: 192195.

Harman GE, Howell CR, Viterbo A, Chet I, Lorito M (2004) Trichoderma speciesopportunistic, avirulent plant symbionts. Nature Reviews 2: 43-56.

Hayat R, Ali S, Amara U, Khalid R, Ahmed I (2010) Soil beneficial bacteria and their role in plant growth promotion: a review. Annals of Microbiolog 60:579598.

Kalavati, P., Sharma, M.C and Modi, H.A. 2012. Optimization of medium components for potassium solubilizing fungus - Aspergillus terreus (Ksf 1) by response surface methodology. Indian Journal of Fundamental and Applied Life Sciences. 2 (4): 54-60.

Khan, M. S. 2006. Screening of free-living rhizospheric bacteria for their multiple plant growth promoting activities. 163:173-181.

Kloepper JW, Leong J, Teintze M, Schroth MN (1980) Enhanced plant growth by siderophores produced by plant growth- 
promoting rhizobacteria. Nature286: 885-886.

Lugtenberg B, Kamilova F (2009) Plantgrowth-promoting rhizobacteria. Annual Review of Microbiology 63: 541-556.

Maheshwar, N.U and Sathiyavani, G. 2012. Solubilization of phosphate by Bacillus spp., from groundnut rhizosphere (Arachis hypogaea L). Journal of Chemical and Pharmaceutical Research. 4 (8): 4007-4011.

Nelson, L. M. 2004. Plant growth promoting rhizobacteria (PGPR): Prospect for new inoculants. Crop Management. doi: 10. 1094/CM-2004-0301-05-RV.

Pazhaniraja, P and Prabudoss, V. 2014. Zinc solubilizing nature of Gluconacetobacter diazotrophicus. Indian Streams Research Journal. 3 (12).

Pikovskaya, R.I. 1948. Mobilization of phosphorus in soil connection with the vital activity of some microbial species. Microbiologiya.17: 362-370.

Prajapati, K.B and Modi, H.A. 2012. Isolation and characterization of potassium solubilizing bacteria from ceramic industry soil. CIB Tech Journal of Microbiology, 1 (2-3) (2012), pp. 8-14

Rehab, M.M. 2015. Biosorption of zinc and cadmium by Klebsiella pneumoniae KM609983 isolated from Sohag, Egypt. Global Advanced Research Journal of Microbiology. 4 (2): 018-026.

Rodriquez, H. and R. Fraga. 1999. Phosphate solubilizing bacteria and their role in plant growth promotion. Biotechnol. Adv., 17(4-5):319-39.

Salamone, I. E. G. 2000. Direct beneficial effects of cytokinin producing rhizobacteria on plant growth.Ph.D. Thesis, University of Saskatchewan, Saskatoon, SK, Canada; 128 Pp.

Saravanan, V.S., Subramoniam, S.R and Raj, S.A. 2003. Assessing in vitro solubilization potential of different zinc solubilizing bacterial ( $\mathrm{ZnSB})$ isolates. Brazilian Journal of Microbiology.34: 121-125.

Schwyn, B. and Neilands, J.B. 1987. Universal chemical assay for the detection and determination of siderophores. Analytical Biochemistry. 160: 47-56.

Van der Ent S, Van Wees SC, Pieterse CMJ (2009) Jasmonate signaling in plant interactions with resistance-inducing beneficial microbes. Phytochemistry70: 1581-1588.

Vazquez, P., G. Holquin, M. E. Puente, A. Lopez-Cortez and Y. Bashan. 2000. Phosphate solubilizing microorganism associated with the rhizosphere of mangroves in a semiarid coastal lagoon. Biol. Fert. Soil 30: 460-468.

Vessey, J. K. 2003. Plant growth promoting rhizobacteria as biofertilizers. Plant Soil 255: 571-586.

Werner, D. 1992. Symbiosis of Plants and Microbes. Chapman and Hall, London.

Yogendra, S., Ramteke, P.W., Pradeep, K and Shukla. 2013. Characterization of Rhizobium spp isolates of pigeon pea rhizosphere from Allahabad soils and their potential PGPR characteristics. International Journal of Research in Pure and Applied Microbiology. 3 (1): 4-7.

\section{How to cite this article:}

Thirumal, G., R. Subhash Reddy, S. Triveni, Y. Nagaraju and Prasannakumar, B. 2017. Screening of Native Rhizobia and Pseudomonas Strains for Plant Growth Promoting Activities. Int.J.Curr.Microbiol.App.Sci. 6(7): 616-625. doi: https://doi.org/10.20546/ijcmas.2017.607.075 